\title{
Sin cuarentena: necropolítica y acción colectiva juvenil en Colombia (2020)
}

\author{
Nicolás Aguilar-Forero, Ph.D. ${ }^{a}$ \\ Universidad de Los Andes, Colombia
}

nj.aguilar1902@uniandes.edu.co

\section{Resumen (analítico)}

La necropolítica se fortaleció en Colombia en medio de la cuarentena causada por el nuevo coronavirus. Como respuesta surgieron diversas formas de protesta, dos de las cuales se analizan en este artículo: la movilización derivada del caso de abuso sexual a una niña emberá por parte de siete militares y la acción colectiva juvenil del movimiento estudiantil, en especial de la Asociación Colombiana de Representantes Estudiantiles de la Educación Superior. El estudio se basa en una aproximación sociocrítica y cualitativa que articula tres técnicas: revisión documental, análisis de contenidos publicados en Twitter y entrevista semiestructurada. Entre los resultados se evidencia que, frente a la necropolítica, la acción colectiva juvenil reaccionó desplegando su potencial transformador por medio de la combinación del ciberactivismo y la movilización «desobediente» en las calles.

\section{Palabras clave}

Violencia, participación juvenil, movimiento estudiantil, ciberactivismo.

\section{Thesauro}

Tesauro de Ciencias Sociales de la Unesco.

\section{Para citar este artículo}

Aguilar-Forero, N. (2021). Sin cuarentena: necropolítica y acción colectiva juvenil en Colombia (2020). Revista Latinoamericana de Ciencias Sociales, Niñez y Juventud, 19(1), 1-23.

https://dx.doi.org/10.11600/rlcsnj.19.1.4539

\section{Historial}

Recibido: 14.09.2020

Aceptado: 09.11.2020

Publicado: 15.12.2020

\section{Información artículo}

Este artículo es el resultado de un estudio exploratorio e independiente realizado por el autor desde el 25 de marzo de 2020 hasta el 30 de junio del mismo año. Área: ciencias sociales. Subárea: interdisciplaria/antropología. 


\section{No lockdown: necropolitics and collective youth action in Colombia (2020)}

\section{Abstract (analytical)}

Necropolitics was strengthened in Colombia during the lockdown caused by the new coronavirus. In response, different forms of protest emerged, two of which are analyzed in this article: the mobilization regarding the case of sexual abuse of an Emberá girl by seven soldiers; and the collective youth action of the student movement, especially the Colombian Association of Higher Education Student Representatives. This study is based on a socio-critical and qualitative approach that articulates three techniques: document review, analysis of content published on Twitter and semi-structured interviews. The results evidence that, in the face of necropolitics, youth collective action reacted by displaying its transformational potential through the combination of cyber-activism and "disobedient" mobilization on the streets.

Keywords

Violence, youth participation, student movement, cyberactivism.

\section{Sem quarentena: necropolítica e ação coletiva juvenil na Colômbia (2020)}

\section{Resumo (analítico)}

A necropolítica foi fortalecida na Colômbia em meio à quarentena causada pelo novo coronavírus. Em resposta, surgiram várias formas de protesto, duas das quais analisadas neste artigo: a mobilização derivada do caso de abuso sexual de uma menina Emberá por sete soldados e a ação coletiva da juventude do movimento estudantil, especialmente a Associação Colombiana de Representantes de Estudantes do Ensino Superior. O estudo é baseado em uma abordagem sócio-crítica e qualitativa que articula três técnicas: revisão documental, análise de conteúdo publicado no Twitter e uma entrevista semiestruturada. Entre os resultados, é evidente que, diante da necropolítica, a ação coletiva juvenil reagiu ao mostrar seu potencial transformador por meio da combinação de ciberativismo e mobilização "desobediente" nas ruas.

\section{Palavras-chave}

Violência, participação juvenil, movimento estudantil, ciberativismo.

\section{Información autor}

[a] Departamento de Lenguas y Cultura, Universidad de Los Andes, Bogotá. Antropólogo y Profesional en Lenguajes de la Universidad de los Andes. Magíster en Estudios Culturales de la Universidad Javeriana. Doctor en Ciencias Sociales, Niñez y Juventud (Cinde-Universidad de Manizales). (iD) 0000-0002-9181-0281. H5: 7. Correo electrónico: nj.aguilar1902@uniandes.edu.co 


\section{Introducción}

\section{Necropolítica, coronavirus y acción colectiva juvenil}

e manera similar a lo sucedido en otros países latinoamericanos, los últimos
meses de 2019 en Colombia fueron de intensa agitación social y política. El ${ }_{21}$ de noviembre se inició un paro nacional que se prolongó de manera muy activa en las calles y muy visible en los medios hasta enero de 2020. Las causas estuvieron relacionadas, en principio, con el paquetazo neoliberal del presidente Iván Duque, es decir, con las reformas tributaria, pensional y laboral impulsadas por aquel y su partido de gobierno. La articulación de amplios sectores sociales, la confluencia de otros motivos de indignación (incumplimiento de los acuerdos de paz, asesinato de líderes sociales, holding financiero, privatizaciones, corrupción, entre otros), el protagonismo juvenil y el carácter creativo/festivo de las movilizaciones fueron de los rasgos más característicos de este paro nacional (Aguilar-Forero, 2020).

Sin embargo, desde marzo de 2020 la pandemia causada por el nuevo coronavirus produjo efectos globales/locales inesperados y consecuencias en los procesos de revuelta social que estaban en curso. Entre los efectos, además de los miles de muertos y millones de contagiados, se pueden mencionar el crecimiento del desempleo, el aumento exponencial de la pobreza, la proliferación del miedo y la desconfianza, la emergencia de nuevas formas de disciplinamiento y control, la limitación de derechos y libertades, la reducción de las manifestaciones y acciones colectivas en espacios públicos, entre otros.

Varios de estos efectos inciden de manera directa en la vida de los jóvenes. Por ejemplo, como señaló el Departamento Administrativo Nacional de Estadística (2020) para el trimestre marzo-mayo de 2020 el «desempleo de los jóvenes (14 a 28 años) fue de $26.6 \%$, con un incremento de 8.5 p.p. (variación estadísticamente significativa) con respecto al mismo trimestre móvil del año anterior» (p. 7). Para los jóvenes escolarizados la situación no fue mejor, ya que muchos de quienes cursaban educación básica, media o superior, al decretarse la cuarentena vieron suspendido su derecho a la educación, ante la imposi- 
bilidad de acceder o adaptarse a la virtualización de las clases: solo el $4 \%$ de los municipios del país tiene buena conectividad y «el 63\% de los bachilleres del 2018 no tenía acceso a Internet desde sus hogares y, en las zonas rurales, tan solo el $9 \%$ de los jóvenes disponen de computador» (de Zubiría, 2020, § 3). Otros tantos jóvenes, por la frágil situación económica de sus familias y ante la ausencia de alternativas, tuvieron que abandonar el sistema educativo y salir a la calle en busca de algún medio de sustento, alimentando el ejército de trabajadores de la economía de pequeños encargos (gig economy) o incursionando en otras formas de trabajo precario ${ }^{1}$ e informal (Harvey, 2020).

A ello se suma la situación de muchos jóvenes que habitan en barrios periféricos de las ciudades y que viven hacinados en sus hogares, sin acceso o con acceso limitado a servicios públicos esenciales como el agua y en una situación de emergencia alimentaria que se agrava a raíz de la pandemia. Esto evidencia los límites de las medidas de prevención promovidas a nivel nacional, pues « ¿cómo guardar el distanciamiento cuando se vive en hacinamiento?, ¿cómo lavarse las manos si no se cuenta con este servicio?, ¿cómo quedarse en casa si no hay comida?» (Uribe, 2020, § 14). Con estos antecedentes, el objetivo del presente artículo es responder el siguiente interrogante: ¿qué pasa con la acción colectiva juvenil en medio de la cuarentena o aislamiento preventivo obligatorio decretado en Colombia desde el 25 de marzo de 2020?

Para responder esta pregunta es necesario abordar dos conceptos centrales del estudio: necropolítica y acción colectiva juvenil. La necropolítica es una forma de poder difusa y no exclusivamente estatal que reside en la capacidad de decidir quién puede vivir y quién debe morir (Mbembe, 2011). Aunque cuenta con raíces coloniales, la necropolítica encuentra nuevas formas de manifestarse en el contexto de la pandemia causada por el nuevo coronavirus, pues ante el terror de la muerte y en nombre del bien común los regímenes políticos ejercen el poder de matar, de dejar vivir o de exponer a la muerte: grandes poblaciones pasando hambre en confinamientos obligatorios, personal de salud sin suficiente dotación de bioseguridad y en condiciones laborales precarias, ancianos sometidos al darwinismo social, gobernantes que privilegian la economía y la productividad sobre el derecho a la vida o trabajadores informales y precarizados (que en América

${ }^{1}$ Como señala Conti (2004) el término «precario» viene del latín precarius, derivado a su vez de prex, precis (súplica), y significa «obtenido a través de la súplica». Solo después el término ha adquirido el significado genérico de «inestabilidad». No obstante, «no se trata de una inestabilidad feliz, quizá elegida, sino de esa inestabilidad particular dictada por una relación de fuerzas sumamente desfavorable, en la que el trabajo se ha vuelto un bien escaso y al trabajador no le queda más opción que suplicar al capital» (p. 51). 
Latina son alrededor del 50\% de los trabajadores) sometidos a un dilema cruel: morir a causa del virus o morir de hambre si se quedan en casa (Santos, 2020).

Se trata entonces de toda una distribución política de los riesgos y, por tanto, de la posibilidad de vivir o morir que es administrada por los gobiernos. Una compleja gestión que opera bajo la lógica del sacrificio, la cual siempre ha estado en el corazón del neoliberalismo (o necroliberalismo) y en la idea que algunos valen más que otros o que los que tienen poco valor pueden ser descartados (Mbembe, 2020). Además, en un contexto en el que la pandemia democratiza el poder de matar debido a que todos pueden en cierta medida hacerlo cuando sus cuerpos son reducidos a fuentes potenciales de contagio (Mbembe, 2020), se habilita el poder de los gobiernos para limitar libertades y derechos (a la locomoción, a la igualdad, a la alimentación, a la protesta, etc.) y para promover nuevas formas de autocontrol y disciplinamiento (Žižek, 2020) que profundizan el miedo, la desconfianza y la fractura de las relaciones sociales: «quien quiera que sea, incluso un ser querido, no debe acercarse o tocarse» (Nancy, 2020, p. 33).

En este marco, si bien el virus por sí solo no discrimina como se suele exaltar en los grandes medios, la profunda desigualdad socioeconómica y las medidas que toman los gobiernos para afrontarlo garantizan que sí lo haga. Por ejemplo, como bien señala Santos (2020), en situaciones de emergencia las políticas de prevención o contención son selectivas, nunca son de aplicación universal, y medidas como la cuarentena son siempre discriminatorias, pues son más difíciles para algunos grupos que para otros e imposibles para muchos otros más. Pero lo más complejo es que el ejercicio de poder sobre la vida que se ejerce desde la lógica del dejar morir o exponer a la muerte, hace que en un momento en el que muchas personas mueren a causa de la enfermedad poco importe para los gobiernos la protección de los cuerpos menospreciados: indígenas, afrodescendientes, mujeres, trans, discapacitados, jóvenes residentes de periferias pobres, habitantes de calle, inmigrantes indocumentados, entre otros (Santos, 2020).

Ahora bien, la necropolítica, que en lugar de disminuir se fortalece durante la pandemia, produce como respuesta necesaria la emergencia de diversas formas de protesta: protestas del personal médico en busca de mejores condiciones laborales y de bioseguridad, protestas de las familias con hambre y empobrecidas para quienes el confinamiento resulta imposible, protestas de los movimientos de mujeres frente al incremento de los feminicidios y protestas antirracistas ante el asesinato de afrodescendientes por parte de la policía, por mencionar algunos ejemplos. Con esto, la tesis de la despolitización derivada del confinamiento resulta frágil, ya que en medio de la pandemia el mundo -y Colombia 
en particular- experimentaron diversas manifestaciones tanto en las calles como en las redes sociales digitales que contaron con una fuerte presencia juvenil.

Tales expresiones de indignación y protesta pueden ser interpretadas desde el concepto de acción colectiva juvenil. Este agrupa toda forma de intervención colectiva con liderazgo juvenil que está orientada al cambio social y que, en lugar de ser solo contestataria, es también constituyente, pues produce significados, reconstruye mundos y puede promover alternativas frente a la explotación capitalista, el patriarcado y la discriminación racial (Aguilar-Forero, 2016; Aguilera, 2010; Aguilera, 2011; Alvarado et al., 2011; Delgado, 2009; Delgado et al., 2008; Escobar, 2010; Escobar et al., 2001; Santos, 2020).

La acción colectiva juvenil es la expresión de una política de la posibilidad en el aquí y el ahora, que gesta subjetividades, lenguajes, relaciones e incluso formas de ser y existir poscapitalistas. Lo colectivo de esta acción no refiere a un agregado de sujetos similares, sino a la articulación en la diferencia y la acción misma, que se realiza colectivamente; no implica necesariamente una práctica que se origina de manera predeterminada o que sea distinta al pensamiento (Gibson-Graham, 2011). Así mismo, como señala Aguilar-Forero (2020), la acción colectiva juvenil se apoya en cuatro pilares que se refuerzan entre sí y en los cuales reside su poder transformador: la comunicación, la confianza, la colaboración y la construcción de lo común.

La comunicación mediada por tecnologías digitales es un rasgo característico de este tipo de acción, pues muchos colectivos juveniles han utilizado Internet y las redes sociales digitales para coordinar acciones, visibilizar temas silenciados por los grandes medios, generar presión social, circular y producir contenidos críticos o contrainformativos, entre otras formas de ciberactivismo (Bekkers et al., 2011; Fernández-Planells, 2013; Juris, 2012; Linder et al., 2016; Pearson et al., 2016; Peña et al., 2016; Share \& Shayne, 2008; Theocharis, 2012; Valenzuela, 2013). En paralelo, y aunque exista una tendencia cada vez más evidente hacia la convergencia y la comunicación digital, aún se siguen utilizando, como parte de la acción colectiva juvenil, viejas tecnologías (impresos, flayers, boletines) de acuerdo con las posibilidades y necesidades políticas de los colectivos (Rueda, 2013).

La confianza —otro pilar de la acción colectiva juvenil— se gesta a través de redes afectivas y vivencias compartidas por los jóvenes en espacios informales (fiestas, tertulias, etc.), que logran generar unión y sentido de pertenencia a un grupo incluso por encima de los propósitos propiamente políticos (Aguilera, 2010). Estos espacios de intercambio afectivo evitan que la acción colectiva juvenil se formalice, se torne acartonada o se sedimente, pues esta se vincula con el goce, el gusto, el placer y el deseo de estar juntos 
(Figueroa-Grenett, 2018). Del mismo modo, la acción colectiva juvenil está mediada por la colaboración, no solo entre los miembros de un colectivo, sino entre redes más amplias de solidaridad, apoyo mutuo y cooperación. Se trata de redes colaborativas o ensamblajes ${ }^{2}$ que enlazan sujetos, cuerpos, prácticas, organizaciones y relaciones que se mueven entre lo local, lo nacional y lo internacional.

La construcción de lo común, cuarto pilar de la acción colectiva juvenil, depende de la comunicación, la confianza y la colaboración, tomando distintas formas. En diversas ocasiones lo común se basa en malestares compartidos que producen uniones transitorias o articulaciones provisionales. En otras ocasiones lo común toma la forma de comunidad, cuando los grupos humanos en resistencia deben asumir la composición anónima de un todo orgánico e indivisible que haga contrapeso a la represión, el asesinato selectivo y el señalamiento individualizado. La comunidad, en tanto experiencia compartida, permite que la agresión cometida contra uno de sus integrantes sea sentida como una violencia inaceptable para el colectivo y pueda generar el efecto de fortalecer la misma experiencia común (Zibechi, 2010). Con esta base, a continuación se presenta el método para luego exponer los resultados del estudio.

\section{Método}

Esta investigación se soporta en un enfoque epistemológico sociocrítico en el que, en lugar de describir o comprender una realidad externa, se busca contribuir desde la producción de conocimiento a la materialización de los procesos de cambio y resistencia de los que se hace parte. Ello implica asumir una posición que no sea exterior a los procesos de movimiento, sino que se pliegue a ellos, que asuma una posición implicada y entrelazada con las dinámicas de acción colectiva. Como lo explica Escobar (2010), en lugar de validar teorías, el propósito de los proyectos críticos y de la investigación que se

${ }^{2}$ Como explica Escobar (2010) los ensamblajes funcionan bajo la lógica de las redes o mallas y pueden tener los siguientes rasgos: 1) son autoorganizados y crecen en direcciones imprevistas; 2) están constituidos de elementos diversos (humanos y no humanos); 3) existen hibridizados con otras mallas y jerarquías; 4) articulan elementos heterogéneos sin imponerles uniformidad; 5) están determinados por el grado de conectividad que les permite llegar a ser autosustentables; 6) son adaptativos y evolucionan por la deriva provocada por el ambiente, aunque preservan su organización interna; 7 ) implican procesos de desestratificación y reterritorialización de lugares, territorios, regiones e identidades; 8) llevan aparejadas estrategias basadas-en-lugar con estrategias de entretejimiento con otras redes. 
sitúa en este enfoque es concebido como colaboración con los particulares objetivos de los movimientos sociales y políticos.

Desde este enfoque se desarrolló una aproximación cualitativa basada en la revisión documental de 14 artículos de opinión y noticiosos. Los criterios de inclusión y selección de estas fuentes se basaron en tres aspectos: 1) actualidad: que hayan circulado entre marzo y junio de 2020 (momento en el que se redactó el presente texto); 2) diversidad de perspectivas: siete artículos circularon en medios dominantes y siete artículos fueron publicados en medios alternativos; 3 ) autoría diversa: artículos de opinión o noticiosos con autores diferentes, en algunos casos claramente definidos (siete) y en otros con una autoría atribuida al medio de comunicación y no a un sujeto en particular (siete).

La revisión documental se complementó con un análisis sistemático de la cuenta de Twitter de la Asociación Colombiana de Representantes Estudiantiles de la Educación Superior (Acrees). Dicho análisis se basó en las publicaciones de esta cuenta desde el 25 de marzo hasta el 25 de junio de 2020 por medio de una estrategia analítica soportada en dos preguntas de indagación: 1) ¿cuáles son las acciones colectivas juveniles que promueve Acrees desde Twitter?; 2) ¿con qué propósitos explícitos o implícitos se promueven estas acciones? Las publicaciones se agruparon en dos grandes categorías deductivas vinculadas con tales preguntas: 1) acciones colectivas; 2) intencionalidades. Estas categorías, a su vez, se desagregaron en códigos inductivos o emergentes derivados del ejercicio analítico, entre los que se destacan los siguientes: a) «twitteratones»; b) transmisiones en vivo; c) circulación de información; d) creación de contenidos; e) denuncia pública; f) coordinación de acciones; g) promoción de la solidaridad nacional e internacional.

Se optó por analizar y visibilizar la acción colectiva de Acrees debido a que se reconoce su liderazgo, no solo dentro del movimiento estudiantil colombiano, sino también como parte de otras plataformas de convergencia social que han articulado el inconformismo ciudadano en los últimos años en Colombia (Acrees ha hecho parte activa del comité nacional de paro que impulsó las movilizaciones de noviembre de 2019, conocidas como el ${ }_{21} \mathrm{~N}$ ). Aunque Acrees utiliza distintas formas de intervención político-comunicativa, se decidió analizar su cuenta de Twitter @ACREESCOL que suma más de 18000 seguidores por tratarse de una de sus plataformas más activas.

La tercera fuente de información fue una entrevista a una de las dirigentes de Acrees que se vinculó a esta asociación desde sus inicios como representante estudiantil de una universidad privada de Bogotá. Al inicio de la entrevista, que se realizó a través de Zoom el 14 de julio de 2020, se presentó a la entrevistada el objetivo del estudio, se solicitó su 
autorización para grabar la sesión y se aclaró que su identidad sería confidencial. Durante la conversación se formularon las siguientes preguntas: ¿qué es Acrees y cuáles son sus motores de lucha y reivindicación?, ¿cómo llega la entrevistada a Acrees y cómo ha sido su experiencia participando en esta organización?, ¿cuáles han sido las principales acciones colectivas de Acrees antes y durante la cuarentena?

Más que una entrevista se podría decir que la técnica implementada fue el conversatorio, entendido como un proceso por medio del cual se experimentan intercambios de significados entre los distintos interlocutores a partir de algún tema, pregunta o problema objeto de reflexión. Se trata de un dispositivo metodológico de carácter semiestructurado que parte de una temática de especial interés, pero no necesariamente de un cuestionario extenso y preestablecido. Su potencialidad, como señala Haber (2011), radica en que la conversación relacional es un no-método, pues «en lugar de ser un camino que nos conduce al conocimiento es ya un lugar de conocimiento» (p. 33).

La información recolectada de las tres fuentes principales (artículos de opinión, cuenta de Twitter y entrevista) fue procesada, codificada y categorizada en Nvivo 12, software para el análisis de datos cualitativos. Entre los códigos emergentes que se crearon en el proceso de categorización se destacaron dos por su recurrencia en las tres fuentes de información. El nombre que se asignó a dichos códigos es el mismo que se utiliza como título de la siguiente sección: \#Emberaquémonos y \#MatrículoCero

\section{Resultados}

\section{\#Emberaquémonos y \#MatrículoCero}

La necropolítica se agudizó en Colombia en medio de la cuarentena. Según el Observatorio Feminicidios Colombia (2020) desde el 25 de marzo hasta el 25 de junio fueron asesinadas 113 mujeres. El caso de la estudiante de 23 años la Universidad Eafit, Daniela Quiñónez, fue quizás de los más visibles en los medios. Su asesinato tuvo lugar el 14 de junio a manos de un hombre que se ofreció a llevarla a su casa y su cuerpo apareció en el río Cauca con signos de tortura y asfixia (Ruiz-Navarro, 2020). A ello se suma la muerte de seis mujeres trans en menos de un mes, entre las que se encuentra Alejandra Monocuco quien, según lo denunció la Red Comunitaria Trans, murió por negligencia médica y transfobia institucional el 29 de mayo en Bogotá debido a que no la quisieron atender ni trasladar cuando presentó afecciones de salud (Cárdenas, 2020). El aumento de los feminicidios y la violencia de género durante la cuarentena involucró incluso a las fuerzas 
militares, cuando en junio de 2020 se conoció el caso de la violación de una niña emberá chamí de 12 años por parte de siete militares adscritos al Batallón de Artillería San Mateo ubicado en Risaralda (Las2orillas, 2020).

Además de los feminicidios, los juvenicidios que aluden a procesos de precarización, vulnerabilidad, estigmatización, criminalización, desaparición y asesinato sistemático de jóvenes (Reguillo, 2015; Gómez-Agudelo, 2018; Muñoz, 2015, Valenzuela, 2015), tampoco cesaron en medio de la pandemia. Por ejemplo, el zo de mayo de 2020 se conoció el caso de Anderson Arboleda Montaño, un joven afrodescendiente que murió horas después de recibir una golpiza a manos de patrulleros del comando central de Puerto Tejada, Cauca. Anderson tenía 19 años cuando fue víctima de brutalidad policial en frente de su casa por infringir el aislamiento obligatorio. El caso de Anderson se suma a la larga lista de situaciones de brutalidad policial que han afectado a los jóvenes en Colombia, entre las que se incluye la del estudiante de 19 años Dilan Cruz que en noviembre de 2019 fue asesinado luego de recibir un impacto en la cabeza por una bolsa de material textil con perdigones de plomo que disparó el Escuadrón Móvil Antidisturbios, en el marco de las protestas del $21 \mathrm{~N}$ (Morales, 2020).

Ahora bien, los juvenicidios se acompañan por el que es, quizás, el más doloroso ejemplo de violencia estructural y necropolítica en Colombia: el asesinato sistemático de líderes sociales. Según los datos del Instituto de Estudios para el Desarrollo y la Paz (Indepaz, 2020), desde el inicio de la cuarentena el 25 de marzo hasta el 27 de junio fueron asesinados 63 líderes sociales y defensores de derechos humanos, quienes en su mayoría eran indígenas, campesinos y afrodescendientes. Esta cifra se suma a las 914 personas líderes sociales y defensoras de Derechos Humanos que fueron asesinadas en Colombia después de la firma del acuerdo de paz (21 en el año 2016, 208 en el año 2017, 282 en el año 2018, 253 en el año 2019 y 150 hasta el 27 de junio de 2020) y a los más de 200 excombatientes de las Farc también asesinados luego de esta firma (Indepaz, 2020).

Pero entre la violencia, la barbarie y la necropolítica emergen diversas formas de protesta lideradas principalmente por jóvenes, quienes le imprimen nuevos lenguajes a las gramáticas de la resistencia y encuentran novedosas formas de decir nosotros, de autoconvocarse y de gritar que las cosas no pueden seguir así (Reguillo, 2015). Fue esto lo que sucedió el 24 de mayo en el entierro de Anderson Arboleda, cuando centenares de jóvenes marcharon con banderas blancas recorriendo las calles de Puerto Tejada (Morales, 2020). Aunque la respuesta a este hecho no tuvo las dimensiones que, por la misma época, tuvo el asesinato a manos de la policía del afroamericano George Floyd que desencadenó 
movilizaciones multitudinarias en Estados Unidos y Europa en contra de la discriminación racial y el abuso policial, sí permitió llamar la atención de la opinión pública acerca del racismo y la violencia oficial que campean en Colombia.

Por su parte, el caso del acceso carnal violento a una niña emberá a manos de soldados también causó indignación y desató numerosas marchas y plantones desde el 26 de junio para rechazar este hecho y exigir justicia. Los plantones se realizaron durante varios días consecutivos, contaron con una fuerte presencia juvenil y tuvieron lugar, entre otros, frente al batallón de artillería San Mateo, en Pereira, frente al búnker de la Fiscalía General de la Nación y frente al Cantón Norte, en Bogotá.

En el Cantón Norte, el 29 y 30 de junio, centenares de personas con antorchas y pancartas protestaron en principio por el caso de violencia sexual, pero de manera más amplia para exigir el respeto de los derechos de las mujeres, como se escuchó en algunas de las consignas: «La violación de la niña emberá, jla denunciamos, la denunciamos!», «Denunciamos al Ejército violador, jlo denunciamos, lo denunciamos!», «Exigimos los derechos de las mujeres, jlos exigimos, los exigimos!» Si bien estas movilizaciones fueron convocadas a través de redes sociales y con mensajes orientados a preservar las medidas de bioseguridad, la acción colectiva juvenil es desobediente y no se deja reducir del todo por ninguna forma de disciplinamiento y control. Aunque abundaron los tapabocas, el distanciamiento físico fue ignorado por muchas de las personas asistentes («Antorchas se encienden en Bogotá», 2020).

En lugar del distanciamiento físico, en plantones como el que tuvo lugar el 26 de junio frente al Batallón San Mateo, en Pereira, predominó la música, el baile y el canto colectivo de jóvenes, en su mayoría mujeres, que entonaron Un violador en tu camino («Feministas en Pereira», 2020). Este performance, que irrumpió con fuerza en las protestas de octubre de 2019 en Chile y se hizo presente por primera vez en Colombia en el marco del paro nacional de este mismo año, evidencia cómo cuerpos singulares e indisciplinados se encuentran en lo común para gozar, bailar y al mismo tiempo expresar la denuncia frente a un violador, que es la sociedad en sí misma (Aparicio, 2019). Se trata de un buen ejemplo de la potencia del cuerpo que se articula con la indignación, el performance, la música y el ritmo para hacer una denuncia y construir lo común (Mauna-Rivera et al. 2020; Figueroa-Grenett, 2018).

Ahora bien, aunque la acción colectiva juvenil no entra en cuarentena en medio de la pandemia y preserva su presencia desobediente en las calles, en paralelo se fortalecen diferentes prácticas de ciberactivismo. En torno a este mismo caso de violencia sexual a 
manos del Ejército Nacional circularon en redes sociales, en especial en Twitter y Facebook, numerosas piezas comunicativas con por lo menos tres propósitos: 1) denunciar el caso y exigir justicia (a través de una imagen-ícono que muchos publicaron como foto de perfil); 2) convocar para futuras acciones en las calles; 3 ) informar sobre el hecho y promover la solidaridad nacional e internacional.

Entre los hashtags que acompañaron el ciberactivismo en torno a este caso se destacaron \#NiUnaMás\#NiUnaMenos, \#ElEncierroNOmeCalla y \#Emberaquémonos. Este último además hizo parte una campaña en la que diversos artistas, influenciadores y personas del común publicaron fotografías con la mitad de su cara sobrepuesta con la mitad de la cara de una mujer emberá, conformando un solo rostro. A este gesto de empatía y solidaridad con el que se visibilizó y denunció el caso le siguieron, no obstante, distintas críticas en Twitter que dan cuenta de las diferentes expectativas que se tienen frente al activismo social: «A las niñas indígenas no las van a salvar con fotos cortadas por la mitad y un hashtag para ganar likes y posar de correctos»; «Uff, la no indiferencia ahora es una moda: poner el HT, el ícono, etc...»; «Wow, ya salió otra campaña inútil en la que los famosos criollos instrumentalizan una minoría para mostrarse más humanos» (Rozo, 2020). Lo cierto es que, más allá de estas críticas que se retoman más adelante, el activismo alrededor de este caso no se agotó en las redes sociales y por el contrario contó con diversas manifestaciones juveniles en las calles.

Otra experiencia de acción colectiva juvenil presente en medio de la cuarentena es la del movimiento estudiantil. Como se mencionó previamente, una parte de este movimiento converge en Acrees, asociación gremial fundada hace 4 años que agrupa a representantes estudiantiles de todas las regiones de Colombia en torno a un objetivo común:

Defender la educación pública, gratuita y de calidad. La base de nuestra discusión y nuestro problema es la ley zo que básicamente terceriza la educación de Colombia y permite modelos de educación que responden al sistema de producción, sin tener en cuenta otros factores que permitirían que nuestra educación superior tuviera unos objetivos de desarrollo que vayan más allá del desarrollo de capital. (Entrevista dirigente de Acrees, 14 de julio de 2020)

El análisis del contenido de la cuenta de Acrees desde el 25 de marzo hasta el 25 de junio de 2020 permitió identificar tres prácticas político-comunicativas en torno a las cuales giró su acción colectiva durante la cuarentena: «twitteratones», transmisiones en Facebook Live y circulación de contenidos (cartas, solicitudes y comunicados). En este periodo se realizaron ocho «twitteratones» que fueron promovidas con los siguientes 
hashtags: \#IcetexNoAliviaNiConPandemia, \#DuqueSalvelasIES, \#DuqueSalveALasUniversidades, \#SOSEstudiantesUPrivadas, \#GeneraciónEGeneraciónEngañada, \#Elı18MatrículaCero, \#SOSMatrículaCero, \#SOSUNIVERSIDADES. Las «twitteratones»son una forma de acción colectiva que ha usado Acrees durante los últimos años para generar opinión pública y debate en torno a los temas centrales de reivindicación del movimiento estudiantil. En palabras de la entrevistada:

Las twitteratones no las usa Acrees solo desde ahorita. Por la organización que tiene Acrees nosotros ya ponemos fácilmente a 250 personas de acuerdo por región, que están en cargos de representación. La más densa obviamente es regional centro por el número de universidades que tiene esta área, pero las otras regiones también están muy capacitadas y hay líderes muy fuertes en sus universidades, de modo que si citamos una twitteratón realmente sí impactamos y a la hora ya somos tendencia nacional. Se usan no solo por el escándalo, sino porque hay detrás un trabajo argumentativo y de estudio previo para hacerle entender a las personas qué es lo que está pasando. Pero no son solo de ahorita, solo que ahora se notan más porque no tenemos las calles. (Entrevista dirigente de Acrees, 14 de julio de 2020)

Esta acción colectiva ha permitido que otras organizaciones de estudiantes (de economía y de medicina, por ejemplo), así como personas que no están familiarizadas con la lucha estudiantil, se sumen a las peticiones de Acrees y encuentren en las «twitteratones» una oportunidad de identificarse y de sumarse a una causa colectiva. Así mismo, como explicó la entrevistada, en un momento de confinamiento para muchas personas la única forma de participación y expresión es la que posibilita la red, razón por la cual buena parte de los malestares e inconformismos se manifiestan por medio de este tipo de prácticas.

Además de las «twitteratones», en el periodo analizado se realizaron 5 transmisiones en vivo a través de Facebook Live que luego fueron publicadas en Twitter y YouTube. En estas transmisiones tipo conversatorio se informa sobre la situación de las universidades públicas y privadas y se analiza colectivamente «el origen de ciertas decisiones, sus impactos y cuáles son nuestras exigencias» (Entrevista dirigente de Acrees, 14 de julio de 2020). La transmisión más reciente en el periodo de análisis se tituló ¿Por qué el Gobierno Nacional debe asumir la \#MatrículoCero?, y contó con la participación de Jennifer Pedraza y Laura Alzate, representantes estudiantiles de la Universidad Nacional y de la Universidad de Caldas, respectivamente. 
Por último, el activismo digital de Acrees se apoyó en la publicación y circulación viral de comunicados, cartas y solicitudes en su mayoría dirigidas al presidente Iván Duque y a la Ministra de Educación María Victoria Angulo. Desde las primeras cartas que circularon el 27 de abril y el 7 de mayo, Acrees propuso que el Gobierno nacional garantizara la conectividad digital de los hogares que no cuentan con este servicio y medios de subsidio para que los estudiantes pudieran adquirir equipos de cómputo. Así mismo, señaló la importancia de que el Estado asumiera el costo de las matrículas de los estudiantes de instituciones de educación superior públicas para el segundo semestre de 2020, dada la difícil situación económica de las familias, así como que el Gobierno junto con el Icetex implementaran un plan de auxilios con condiciones flexibles que no implicaran incremento en los intereses de los créditos para estudios en universidades privadas que han sido asumidos por los estudiantes (Acrees, 2020)

Este último punto, impulsado también por medio de las «twitteratones» y las transmisiones en vivo, fue recogido en una de las seis peticiones de emergencia que el Comité Nacional de Paro, a través de una carta, presentó al presidente Iván Duque el 19 de junio de 2020: «Apoyo al sistema educativo público dirigido a garantizar la matrícula cero en las instituciones de educación superior pública y subsidios dirigidos a garantizar la continuidad de los estudios en las instituciones de educación superior privada» (Acrees, 2020c, párr. 8).

Tal combinación de acciones colectivas de Acrees permite, en palabras de la entrevistada, que «así no estemos en las calles estemos haciendo una presión justificada frente a las decisiones que se están tomando de manera arbitraria por parte del Gobierno nacional que van en detrimento de las y los estudiantes del país» (Entrevista dirigente de Acrees, 14 de julio de 2020). Aunque Acrees no asumió durante la cuarentena la postura de ir a las calles por el problema de bioseguridad que ello representaba, su ciberactivismo a favor de la matrícula cero resonó entre los estudiantes de Colombia y derivó en plantones en distintas ciudades del país (Valledupar, Cali, Bogotá, Popayán, Pereira, Bucaramanga, Neiva, entre otras).

Estas jornadas incluyeron acampadas por varios días en el caso de los estudiantes de la Universidad Popular del Cesar e incluso huelgas de hambre por parte de estudiantes de la Universidad de los Llanos, la Universidad del Tolima y la Universidad del Valle, para exigir que no se cobrara la matrícula en el segundo semestre de 2020 («Estudiantes de la U. del Valle», 2020). Dicha presión del movimiento estudiantil por medio de una acción 
colectiva simultáneamente online y offline permitió dar un paso adelante en la gratuidad de la educación superior y confrontar la deserción estudiantil proyectada para 2020-2.

La prueba más clara de ello es que varias universidades públicas acogieron la propuesta de matrícula cero: Universidad de Cundinamarca, Universidad de Córdoba, Universidad del Magdalena, Universidad de los Llanos, Universidad del Valle, Instituto Tecnológico Metropolitano de Medellín, Institución Universitaria Pascual Bravo (Medellín), Colegio Mayor de Antioquia y Universidad Distrital Francisco José de Caldas (Bogotá). A pesar de ello, la lucha de los estudiantes continuó en medio de la pandemia en especial debido a que las medidas del Gobierno para apoyar a las universidades no respondieron a sus expectativas ni a lo que implica asumir la educación como un derecho fundamental (gratuidad, disponibilidad y pertinencia). Así lo denunció Acrees en uno de los últimos tweets del periodo de tiempo analizado: «Aunque existen recursos para rescatar las IES estatales, auxiliar usuarios de Icetex y auxiliar a IES privadas, las medidas del gobierno se han reducido a distintas modalidades de crédito, aun cuando no es claro si las IES y las familias podemos pagarlos \#SOSMatrículaCero» (Acrees, 2020a [Tweet 17 de junio]).

\section{Discusión}

El estado emergencia causado por la pandemia es el terreno fértil para limitar derechos y ejercer violencia en contra de los jóvenes y de la población en general, en nombre del bienestar común. La necropolítica no entra en cuarentena y, por el contrario, el asesinato de líderes sociales, los feminicidios y juvenicidios continúan, con la participación por acción o por omisión de las instituciones del Estado. En este marco el poder, que no es necesariamente un poder estatal, invoca permanentemente la excepción, la urgencia y una noción ficcionalizada de enemigo (el virus como enemigo invisible), para producir esta misma excepción, urgencia y temor al enemigo (Mbembe, 2011).

El miedo, administrado como recurso político y comunicativo, permite que se profundice la vigilancia, el control y la militarización de la vida cotidiana acompañada de toques de queda y confinamientos selectivos. En paralelo, como se ha hecho en Colombia, se implementan medidas para favorecer a los bancos y a los grandes empresarios en detrimento de la preservación de la vida y de la garantía de los derechos fundamentales a la salud y a la educación. Pese a ello, el cuerpo, convertido en objeto de protección contra el peligro y la muerte causada por el coronavirus, responde con movilización y acción 
colectiva. Durante la cuarentena las prácticas de violencia estructural y necropolítica se ven confrontadas por una acción colectiva juvenil que encuentra formas de desplegar su potencial transformador combinando el ciberactivismo con la movilización desobediente en las calles.

Como se ilustra en el caso de Acrees, el ciberactivismo se manifiesta en diversas prácticas político-comunicativas (twitteratones, transmisiones en vivo, circulación de comunicados, cartas y solicitudes) con las que se genera presión a favor, entre otros, de la matrícula cero. También incluye en otros casos la creación y difusión de campañas o piezas comunicativas - como \#Emberaquémonos-que permiten denunciar una situación de violencia, convocar para futuras acciones en las calles, exigir justicia y promover la solidaridad nacional e internacional. Sin embargo, como se mencionó previamente, estas prácticas de activismo digital no han escapado a las críticas. Para algunos el ciberactivismo se reduce a una forma de concientización que implica poco tiempo, mínimo esfuerzo y nula participación en movilizaciones o acciones con un efecto demostrable en la solución de problemas sociales (Glenn, 2015).

Según los críticos se trata de dinámicas que no corresponden al activismo real, por cuanto se basan solamente en hacer parte de un grupo o página, firmar peticiones virtuales, demostrar agrado (likes) frente a ciertos contenidos o exaltar la solidaridad al cambiar la foto de perfil e incluir alguna imagen-ícono como la que circuló a propósito de la niña emberá víctima de violencia sexual. El ciberactivismo desde esta óptica no sería más que slacktivism (híbrido de slacker y activism), el cual implica una acción de bajo compromiso (solo clics para apoyar una causa) que otorga algún tipo de satisfacción emocional a las personas, pero impide un conocimiento mayor de las complejidades de los contextos o de la profundidad de las situaciones en torno a las cuales se protesta (LaRiviere et al., 2012; Glenn, 2015).

No obstante, los resultados del presente estudio al igual que otros estudios previos (Aguilar-Forero, 2017; Chiluwa \& Ifukor, 2015; Linder et al. 2016; Metzger et al., 2015; Valenzuela, 2013) evidencian que el ciberactivismo y, en particular, la acción colectiva juvenil combina niveles de participación y de involucramiento diversos que transitan entre lo online/offline y que pueden llegar a tener efectos empíricos demostrables. Lo que muestran los hallazgos de este estudio es que la cuarentena potenció un abanico de prácticas político-comunicativas que favorecieron modalidades de vinculación para movilizar y alcanzar propuestas colectivas, que llegaron incluso a producir consecuencias concretas: matrícula cero en varias universidades públicas del país. 
Ello fue posible por las dinámicas de comunicación y participación en el ciberespacio como las «twitteratones» o las transmisiones en vivo, que no solo propiciaron la visibilidad de ciertos temas sino también la construcción de solidaridades que se extendieron a otros contextos de experiencia y se vincularon con la política callejera: plantones, performances, acampadas, huelgas de hambre. Así mismo, gracias a las tecnologías digitales y a las herramientas de Internet, en especial Twitter y Facebook, se promovió una «práctica política flexible» (Galcerán, 2009, p. 197) que dotó de dinamismo a la acción colectiva y permitió transferir de manera rápida conocimientos y contenidos, así como coordinar acciones y colaborar desde los recursos y posibilidades disponibles.

Esta acción colectiva, profundamente comunicativa, se apoyó también en redes de confianza y colaboración. Como lo han mostrado estudios previos (Aguilar-Forero, 2016; Aguilera, 2010; Aguilera, 2011; Alvarado et al., 2011; Delgado, 2009; Delgado et al., 2008; Uribe-Zapata, 2019), los colectivos y movimientos no existen por sí solos, sino que están imbricados con otras redes e integran con ellas poderosos campos discursivos y relacionales de intervención. En el caso de Acrees sus acciones se desarrollan en colaboración con otros, entre los que se encuentran las asociaciones y organizaciones sociales que integran el Comité Nacional de Paro, y es precisamente esta conexión la que posibilita una mayor presión e incidencia pública. No se trata entonces de una acción solipsista o autorreferencial, pues como se indica en la descripción de la cuenta de Twitter de Acrees, lo que se busca es «juntar voluntades para hacer de la educación un derecho fundamental».

A manera de cierre es importante destacar que el ejercicio investigativo expresado en este artículo lleva a reflexionar sobre dos aspectos que pueden ser, a su vez, limitaciones del presente estudio. En primer lugar, investigar en contextos de confinamiento desde luego tiene sus desventajas: pocas posibilidades de compartir con otros, de vincularnos hombro a hombro con la política callejera, de investigar desde el cuerpo en movimiento y no desde la silla que lo amarra a un lugar fijo detrás de la pantalla. Pese a ello, tal condición particular además de retarnos como investigadores y llevarnos a ser recursivos para poder adaptarnos a esta atípica coyuntura, abre posibles líneas de investigación ligadas, precisamente, a lo que implica investigar en contextos pandémicos: qué pasa con el cuerpo, con las interacciones, con las emociones, con las metodologías y las técnicas, son solo algunas de las reflexiones que quedan abiertas.

En segundo lugar, investigar procesos en curso y formas de acción colectiva juvenil que cambian y se reconfiguran a velocidades cada vez más aceleradas supone lograr que la producción de conocimiento y su circulación puedan ser también muy flexibles y ágiles. 
La acción colectiva juvenil aparece y desaparece en cortos periodos de tiempo, se transforma, asume composiciones diferentes y pocas veces se sedimenta en alguna identidad estable o duradera. Entretanto, los investigadores tardamos mucho tiempo sometidos a los lentos procesos de publicación de muchas revistas especializadas que en ocasiones desfavorecen la circulación libre y oportuna del conocimiento.

Esto hace que necesariamente tengamos que estudiar movimientos u organizaciones más formales y que perduran en el tiempo, pues si decidimos trabajar en torno a formas de acción colectiva juvenil más difusas y cambiantes lo más seguro es que, cuando nuestros textos sean publicados (a veces hasta dos años después de su escritura), estas ya hayan desaparecido o hayan mutado. A pesar de esto toda producción de conocimiento o trabajo investigativo, independientemente de sus tiempos de desarrollo y publicación, afecta y modifica los cuerpos y las subjetividades de aquellos que participan en el proceso; de manera que, así como el pensamiento colectivo genera práctica común, «la producción de conocimiento crítico genera cuerpos rebeldes y el pensamiento sobre las prácticas de rebeldía da valor y potencia a esas mismas prácticas» (Malo, 2004, p. 35).

\section{Referencias}

Acrees [@ACREESCOL] (2020a). [cuenta de Twitter]. Twitter. https://twitter.com/ ACREESCOL y familias. https://bit.ly/2Weictc

Acrees [@ACREESCOL]. (2020b,28 de abril). En carta al Presidente@IvanDuque y @Mineducacion solicitamos asumir matrículas e inyectar más presupuesto a Universidades e ITTU Públicas. [Imagen con enlace]. [Tweet]. Twitter. https://bit.ly/3ngghQF

Acrees [@ACREESCOL]. (2020c,20 de junio). Desde el Comité Nacional de Paro frente a la actual crisis derivada de recesión económica y pandemia, consideramos es prioritario. [Imagen con enlace]. [Tweet]. Twitter. https://bit.ly/3nfuLzj

Aguilar-Forero, N. (2016). Comunica(c)ción: la comunicación en la acción colectiva juvenil: dos experiencias organizativas en la ciudad de Bogotá. Revista Latinoamericana de Ciencias Sociales, Niñez y Juventud, 14(2), 1331-1344.

Aguilar-Forero, N. (2017). Ciberactivismo y olas de agitación comunicativa: consideraciones etnográficas. Íconos, (59), 123-148. https://doi.org/fmgq

Aguilar-Forero, N. (2020). Las cuatro co de la acción colectiva juvenil: el caso del paro nacional de Colombia (noviembre 2019-enero 2020). Análisis Político, 33(98), 26-43. https://doi.org/10.15446/anpol.v33n98.89408 
Aguilera, O. (2010). Acción colectiva juvenil: de movidas y finalidades de adscripción. Revista Nómadas, (32), 81-98.

Aguilera, O. (2011) Acontecimiento y acción colectiva juvenil: el antes, durante y después de la rebelión de los estudiantes chilenos en el 2006. Propuesta Educativa, (35), 11-26.

Alvarado, S. V., Botero, P., Cardona, M., Patiño, J., \& Ospina, H. F. (Eds.) (2011). Experiencias alternativas de acción política con participación de jóvenes en Colombia. Centro de Estudios Avanzados en Niñez y Juventud.

Antorchas se encienden en Bogotá en protesta por violación de niña indígena. (2020, 1 de julio). La Vanguardia. https://bit.ly/2W9icLd

Aparicio, J. R. (2019, 8 de diciembre). El paro también es fiesta: entre lo crítico y el peligro de lo banal. Cerosetenta. https://bit.ly/2K4kGYC

Bekkers, V., Beunders, H., Edwards, A., \& Moody, R. (2011). New media, micromobilization, and political agenda setting: Crossover effects in political mobilization and media usage. The Information Society, 27 (4), 209-219. https://doi.org/bszcmj

Cárdenas, V. (2020, 2 de julio). La lucha de la comunidad trans durante la pandemia en Bogotá. El Espectador. https://bit.ly/37gExMY

Chiluwa, I., \& Ifukor, P. (2015). «War against our children»: Stance and evaluation in \#BringBackOurGirls campaign discourse on Twitter and Facebook. Discourse \& Society, 26(3), 267-296. https://doi.org/10.1177/0957926514564735

Conti, A. (2004). La encuesta hoy. De la «coinvestigación obrerista» al «caminar preguntando» y más allá: la encuesta sobre las «formas de vida» en el «taller metropolitano del saber difuso». En M. Mala (Ed.), Nociones comunes: experiencias y ensayos entre investigación y militancia (pp. 55-66). Traficantes de Sueños.

Departamento Administrativo Nacional de Estadística. (2020, 30 de junio). Comunicado de prensa. Gran Encuesta Integrada de Hogares (GEIH). https://bit.ly/34aAxfg

Delgado, R. (2009). Acción colectiva y sujetos sociales: análisis de los marcos de justificación ético-políticos de las organizaciones sociales de mujeres, jóvenes y trabajadores. Pontificia Universidad Javeriana.

Delgado, R., Ocampo. A., \& Robledo, A. (2008). La acción colectiva juvenil: un modelo de análisis para su abordaje. Ponto-e-vírgula, (4), 196-216.

De Zubiría, J. (2020, 4 de junio). La educación en tiempos de cuarentena. Semana. https://bit.ly/3nfnf8R

Escobar, A. (2010). Territorios de diferencia: lugar, movimientos, vida, redes. Envión Editores. Escobar, A., Álvarez, S. \& Dangino, E. (2001). Lo cultural y lo político en los movimientos sociales latinoamericanos. En A. Escobar, S. Álvarez, \& E. Dangino (Eds.), Política 
cultural y cultura política (pp. 17-47). Taurus; Instituto Colombiano de Antropología e Historia.

Estudiantes de la U. del Valle realizan huelga de hambre para pedir que no se cobre matrícula de este semestre. (2020, 18 de junio). El Espectador. https://bit.ly/2WadzzB

Feministas en Pereira realizaron plantón por violación de niña indígena. (2020). kienyke.com. https://bit.ly/zafhtQH

Fernández-Planells, A. (2013). \#acampadabcn: el 15M desde Catalunya. En C. Feixa, \& J. Nofre (Eds.), Generación indignada: topías y utopías del 15M (pp. 87-116). Milenio.

Figueroa-Grenett, C. (2018). La acción política de niños, niñas y jóvenes en Chile: cuerpos, performatividad y producción de subjetividad. Revista Latinoamericana de Ciencias Sociales, Niñez y Juventud, 16(1), 199-212. https://doi.org/10.1160o/1692715x.16111

Galcerán, M. (2009). Deseo (y) libertad: una investigación sobre los presupuestos de la acción colectiva. Traficantes de Sueños.

Gibson-Graham, J. K. (2011). Una política poscapitalista. Siglo del Hombre; Pontificia Universidad Javeriana.

Glenn, C. L. (2015). Activism or slacktivism?: Digital media and organizing for social change. Communication Teacher, 29(2), 81-85. https://doi.org/fnm5

Gómez-Agudelo, J. W. (2018). Acontecimiento y escucha: revisión de estudios sobre el estudiante caído y los movimientos estudiantiles en Colombia. Revista Latinoamericana de Ciencias Sociales, Niñez y Juventud, 16(1), 71-87. https://doi.org/fnm6

Haber, A. (2011). Nometodología payanesa: notas de metodología indisciplinada. Revista Chilena de Antropología, (23), pp. 9-49. https://doi.org/10.5354/0719-1472.2011.15564

Harvey, D. (2020). Política anticapitalista en tiempos de coronavirus. En P. Madero (Ed.), Sopa de Wuhan: pensamiento contemporáneo en tiempos de pandemias (pp. 79-98).

Aislamiento Social Preventivo y Obligatorio.

Instituto de Estudios para el Desarrollo y la Paz. (2020). Líderes sociales y defensores de derechos humanos asesinados en 2020. https://bit.ly/2LxCGey

Juris, J. (2012). Reflections on \#Occupy everywhere: Social media, public space, and emerging logics of aggregation. American Ethnologist, 39(2), 259-279. https://doi.org/ 10.1111/j.1548-1425.2012.01362.x

LaRiviere, K., Snider, J., Stromberg, A., \& O’Meara, K. (2012). Protest: Critical lessons of using digital media for social change. About Campus, 17(3), 10-17. https://doi.org/ $10.1002 / \mathrm{abc} .21081$

Laszorillas. (2020, 25 de junio). Diez casos de abuso sexual que avergüenzan al ejército. Laszorillas. https://bit.ly/381vTBb 
Linder, Ch., Myers, J. S., Riggle, C., \& Lacy, M. (2016). From margins to mainstream: Social media as a tool for campus sexual violence activism. Journal of Diversity in Higher Education, 9(3), 231-244. https://doi.org/10.1037/dheooooo38

Malo, M. (2004). Prólogo. En M. Malo (Ed.), Nociones comunes: experiencias y ensayos entre investigación y militancia (pp. 13-39). Traficantes de Sueños.

Mauna-Rivera, W. A., Jiménez-López, G. H., \& Galak, E. L. (2020). Cuerpo y política en jóvenes del movimiento estudiantil universitario (Universidad del Cauca, Colombia). Revista Latinoamericana de Ciencias Sociales, Niñez y Juventud, 18(1), 1-20. https:// doi.org/10.11600//1692715x.18102

Mbembe, A. (2011). Necropolítica. Melusina.

Mbembe, A. (2020, 31 de marzo). La pandemia democratiza el poder de matar. [Entrevista de Diogo Bercito a Achille Mbembe]. La Vorágine. https://bit.ly/2LzFhEP

Metzger, M. W., Erete, S. L., Barton, D. L. Desler, M. K., \& Lewis, D. A. (2015). The new political voice of young Americans: Online engagement and civic development among first-year college students. Education, Citizenship and Social Justice, 10(1), 55-66. https://doi.org/10.1177/1746197914558398

Morales, J. D. (2020, 10 de junio). Anderson Arboleda tampoco volvió a respirar. El Espectador. https://bit.ly/zagFCZo

Muñoz, G. (2015). Juvenicidio en Colombia: crímenes de Estado y prácticas socialmente aceptables. En J. M. Valenzuela (Coord.), Juvenicidio: Ayotzinapa y las vidas precarias en América Latina y España (pp. 131-164). NED; Iteso; El Colegio de la Frontera Norte.

Nancy, J. L. (2020). Excepción viral. En P. Amadeo (Ed.), Sopa de Wuhan: pensamiento contemporáneo en tiempos de pandemias (pp. 31-33). Aislamiento Social Preventivo y Obligatorio.

Observatorio Feminicidios Colombia. (2020). Vivas nos queremos: dossier de feminicidios en cuarentena. http://observatoriofeminicidioscolombia.org/

Pearson, E., Tindle, H., Ferguson, M., \& Litchfield, C. (2016). Can we tweet, post, and share our way to a more sustainable society? A review of the current contributions and future potential of \#Socialmediaforsustaintability. Annual Review of Environment and Resources, 41, 363-397. https://doi.org/10.1146/annurev-environ-110615-090000

Peña, P., Rodríguez, R, \& Sáez, C. (2016). Movimiento estudiantil en Chile, aprendizaje situado y activismo digital: compromiso, cambio social y usos tecnológicos adolescentes. Obets. Revista de Ciencias Sociales, 11(1), 287-310.

Reguillo, R. (2015). La turbulencia en el paisaje: de jóvenes, necropolítica y 43 esperanzas. En J. M. Valenzuela (Coord.), Juvenicidio: Ayotzinapa y las vidas precarias en América Latina y España (pp. 59-78). NED; Iteso; El Colegio de la Frontera Norte. 
Rozo, K. (2020). Críticas en redes sociales por campaña de influenciadores y niña indígena. Caracol Radio. https://bit.ly/2KpoBfn

Rueda, R. (2013). Educación, nuevas formas de subjetividad social y tecnologías [Prólogo]. En R. Rueda, L. Ramírez, \& A. Fonseca (Eds.), Ciberciudadanías: cultura política y creatividad social (pp. 4-21). Universidad Pedagógica Nacional. https://doi.org/ $10.2307 /$ j.ctvfc $52 f_{4} \cdot 3$

Ruiz-Navarro, C. (2020, 25 de junio). Pandemia de feminicidios en Colombia. El Espectador. https://bit.ly/zoSc1Yj

Santos, B. (2020). La cruel pedagogía del virus. Clacso.

Share, R. A., \& Shayne, J. (2008). Youth-adult partnership in community organizing: A case study of the my voice counts! campaign. Journal of Community Practice, 14(4), 113-127. https://doi.org/10.1300/J125v14no4_07

Theocharis, Y. (2012). Cuts, tweets, solidarity and mobilisation: How the Internet shaped the student occupations. Parliamentary Affairs, 65(1), 162-194. https://doi.org/10.1093/ $\mathrm{pa} / \mathrm{gsro} 49$

Uribe, M. (2020). Subsidios para los más pobres: ¿qué está pasando en Colombia? Razón Pública. https://bit.ly/3gKXU3T

Uribe-Zapata, A. (2019). Cultura digital, juventud y prácticas ciudadanas emergentes en Medellín, Colombia. Revista Latinoamericana de Ciencias Sociales, Niñez y Juventud, $17(2), 1-19$. https://doi.org/10.1160o/1692715x.17218

Valenzuela, J. M. (2015). Remolinos de viento: juvenicidio e identidades desacreditadas. En J. M. Valenzuela (Coord.), Juvenicidio: Ayotzinapa y las vidas precarias en América Latina y España (pp. 15-58). NED; Iteso; El Colegio de la Frontera Norte.

Valenzuela, S. (2013). Unpacking the use of social media for protest behavior: The roles of information, opinion, expression, and activism. American Behavioral Scientist, 57(7), 920-942. https://doi.org/10.1177/0002764213479375

Zibechi, R. (2010). América Latina: contrainsurgencia y pobreza. Desde Abajo.

Žižek, S. (2020). El coronavirus es un golpe al capitalismo a lo Kill Bill... En P. Amadeo (Ed.), Sopa de Wuhan: pensamiento contemporáneo en tiempos de pandemias (pp. 21-28). Aislamiento Social Preventivo y Obligatorio. 